\title{
O OBJECTO ESTÉTICO COMO MUNDO, NA PHÉNOMÉNOLOGIE DE L' EXPÉRIENCE ESTHÉTIQUE I, DE MIKEL DUFRENNE
}

\author{
Carlos Nogueira da Silva
}

\begin{abstract}
"O objecto estético é a obra de arte enquanto percepcionada. Entre os dois, existe apenas essa única diferença de que una consciência interveio, uma consciência que se faz tão discreta e dócil quanto possivel, mas que faz passar o objecto da noite à luz, do estado de coisa ao estado de percepcionado.»'
\end{abstract}

\section{I - O objecto estético como obra de arte percepcionada}

O que é uma obra de arte? Em primeiro lugar, trata-se de algo que existe no mundo, como um pedra ou uma árvore, susceptível de ser percepcionada como um objecto entre outros objectos. Além disso, podemos desde logo dizer que, contrariamente aos objectos naturais, ela é o produto de um fazer, o resultado de uma actividade humana, do mesmo modo que o são uma mesa ou uma cadeira. No entanto, o seu estatuto de obra de arte leva-nos a pressupor uma nova circunscrição no domínio dos objectos produzidos pelo homem, de tal mod que a obra de arte se destaque daquilo que vulgarmente designamos por objectos utilitários. Todavia, como precisar o critério de demarcação entre estas duas classes de objectes? Sem dúvida que o critério da utilidade se pode apresentar como uma possibilidade. Assim, quando um objecto tem para nós o carácter de um meio que usamos para atingir um determinado fim, e cuja significação, portanto, remete para algo

' Mikel Dufrenne, Phénoménologie de l'expérience esthétique l, Paris, Presses Universitaires cle France, 1992, p. 297

Phainomenon, n. ${ }^{0}$ 3, Lisboa, Edições Colibri, 2001, pp. 57-66

DOI: $10.2478 /$ phainomenon-2001-0010 
que o transcende, apelidamo-lo de utilitário. Negativamente, a obra de arte surgiria como o objecto que não serve para nada, isto é, algo que se nos oferece para que a aceitemos por si mesma, sem que possamos discernir o seu significado por referência a algo que lhe seja exterior, como no caso da perspectiva utilitária. Todavia, este critério sugere de algum modo que o estatuto do objecto dependa mais do modo como nos posicionamos face a ele, e menos da sua natureza intrínseca; se o aceitarmos sem reservas, parecem seguir-se consequências insustentáveis.

É verdade que qualquer um pode usar um quadro de Van Gogh como um objecto utilitário, colocando-o junto a uma vidraça partida de modo a impedir a entrada do vento. Mas será que, desse modo, o quadro em questão perderia o seu carácter de obra de arte? Ou, pelo contrário, teria a sua natureza sido frustrada por uma apropriação cega àquilo que constitui a sua vocação fundamental? Como observa Dufrenne, a obra de arte, na medida em que se encontra no mundo, «pode ser apreendida numa percepção que negligencie a sua qualidade estética». ${ }^{2}$ Para que a obra de arte realize a sua vocação, ela tem que ser objecto de uma percepção que faça justiça à sua natureza, convertendo-a em objecto estético. Isto não significa de modo algum, como sublinha Dufrenne, que o objecto estético se identifique com as representações do sujeito. O objecto estético é a obra de arte na medida em que esta é percepcionada, mas em que o modo da percepção está ao serviço da obra, satisfazendo uma exigência que lhe é própria. Se «a vocação da obra de arte é a de se transcender em direcção ao objecto estético no qual atinge a sua consecução, a plenitude do seu ser» ${ }^{3}$, a percepção estética surge como o requisito indispensável para que, através da consciência do sujeito, se opere essa passagem de uma exigência a uma realização. O objecto estético será então o acontecer da obra de arte mediante uma percepção que, ao invés de se constituir como uma representação subjectiva, reclama uma consciência despojada onde se possa constituir o espaço de manifestação de uma presença; nas palavras de Dufrenne, «a percepção estética funda o objecto estético, mas fazendo-lhe justiça, submetendo-se a ele». ${ }^{4}$

A percepção estética reveste-se de uma particularidade pela qual Dufrenne a define como percepção pura. Esta designação justifica-se plenamente, dado que se trata de uma percepção cujo significado não reenvia para além de si mesma. A sua especificidade torna-se bem clara se a compararmos com outro tipo de percepções, nas quais as preocupações cognitiva e prática orientam a percepção e tendem a ultrapassar a dimensão de uma pura presença do sensível. Assim acontece quando o percepcionado é compreendido no âmbito de um processo cognitivo, em que o diverso do sensível se

\footnotetext{
2 Idem, p. 9

${ }^{3}$ Idem, p. 33

${ }^{4}$ Idem, p. 9
} 
subsume na unidade do conceito, e em que a percepção do sensível desemboca numa significação conceptual. Do mesmo modo a percepção interessada, na medida em que integra o objecto num esquema prévio de finalidades, interpreta-o, em terminologia heideggeriana, como ente disponível, usado e ultrapassado na referência a um mundo de significados e relações. Na verdade, só na experiência estética a percepção é vivida como um absoluto, só nela o sensível se apresenta soberanamente transportando o seu próprio sentido. Mas exploremos ainda esta distinção entre os diversos modos da percepção, com o intuito de aprofundarmos mais a questão que nos ocupa, a asber, qual o ser do objecto estético.

A percepção do tipo «teórico» tende a reduzir o objecto a um «ente em face», situando-o num mundo entendido como um conjunto dado de objectos, realidades substanciais dadas e conhecidas pelos seus atributos. Correlativamente, esta percepção pressupõe um puro sujeito de conhecimento que, guindado acima da sua condição afectiva e existencial, vise a descrição do «dado» como pura objectividade. Por outro lado, a percepção do tipo «prático», como já observámos, refere-se a um ente disponível, pressupondo já um mundo antecipado de significações por relação ao qual ganha o seu sentido. O sujeito dessa percepção, por seu turno, é um sujeito historicamente situado, já lançado num modo de ser ôntico determinado. Vemos assim que, em ambos os casos, existe previamente uma noção de mundo a partir da qual se interpretam as noções de sujeito e objecto. Pelo contrário, no caso da experiência estética, estas dimensões estão em aberto.

O objecto estético não é um ente em face nem um ente disponível, porque ele não aparece como objecto de um mundo já constituído. E como o objecto estético não tem um mundo, a sua significação não apela para uma qualquer exterioridade. Não é um objecto a conhecer, nem uma coisa a usar, mas algo que se impõe precisamente na medida em que rompe com as significações atribuídas pelos mundos estabelecidos. Sem dúvida que a obra de arte pode sempre ser abordada de uma perspectiva cognitiva ou utilitária. Todavia, para que se possa metamorfosear em objecto estético, exige uma percepção pura, manifestando a sua própria significação sem referência a uma exterioridade, e instituindo-se ela própria como um mundo.

Por outro lado, e quanto ao sujeito da percepção, também aqui o domínio do estético se distancia dos demais. Quando ouvimos uma sonata ou quando contemplamos um quadro deixamo-nos invadir pela sua pregnância, negligenciando as dimensões do conhecimento ou do interesse. De facto, toda a experiência estética autêntica se instala como uma descontinuidade no fluxo das nossas vivências habituais, no seio das quais nos encontramos já auto-interpretados. Em grande parte, e face à magia do momento estético, apaga-se a memória do que somos ou julgamos ser, cessamos de existir enquanto projecção de uma subjectividade, submetendo-nos a um acontecimento que se realiza num acolhimento interior, mas que procede de uma 
iniciativa que nos ultrapassa; como diz Dufrenne, é como se o sujeito se irrealizasse para proclamar a realidade da obra, entrando no novo mundo que ela lhe abre, homem novo ele próprio. ${ }^{5}$ Assim, o sujeito da percepção estética é de alguma forma coexistente com o mundo da obra. Por um lado, o objecto estético implica uma percepção, pela qual o mundo da obra se revela numa consciência; todavia, e de certo modo, o verdadeiro sujeito dessa percepção não lhe pré-existe, pois como que é posto por ela. Se é certo, como observa Dufrenne, que é a consciência a fazer com que o objecto «passe da noite à luz», importa salvaguardar alguns pontos essenciais. Em primeiro lugar, que essa luz não é projectada pelo sujeito, mas constitui a própria verdade do objecto. Em segundo lugar, que essa verdade tem que ser uma presença viva, pelo que reclama manifestar-se na interioridade da consciência. Finalmente, que o objecto estético nunca se dá como objecto para um sujeito, dado que este último está intimamente comprometido no seu aparecer, mas apenas numa experiência vivida.

O movimento pelo qual a obra de arte se converte em objecto estético reside pois na passagem de uma exigência a uma realização. E essa realização implica desde logo que a obra seja executada e se manifeste no sensível, ou seja, que a partitura seja tocada, que o bailado seja dançado e a peça teatral representada, pois só assim se pode oferecer como objecto estético. Todavia, e para que o sentido imanente a estas forma de organização do sensível se manifeste plenamente, é necessário que, através de uma percepção, seja reconhecido numa consciência. A obra de arte surge assim como «o objecto estético no estado de um possível aguardando a sua epifania» ${ }^{6}$, até que, com a colaboração do executante e do espectador, se revele uma vez mais na verdade do seu aparecer sensível.

\section{II - A expressão como o modo de significar do objecto estético}

O objecto estético tem o ser de uma significação. ${ }^{7}$ Todavia, como já referimos, trata-se de uma significação que não se constitui por referência a algo exterior ao próprio objecto, ou seja, que não se compreende como cartografia de um mundo já dado. Os signos estéticos não são pois instrumentos que veiculem significações prévias, reenviando-nos para um mundo real de objectos ou acontecimentos por relação aos quais pudéssemos aferir do seu sentido. A peculiaridade do objecto estético, enquanto objecto significante, consiste numa imanência da significação ao signo, ou seja, nele o significado é imanente ao significante. ${ }^{8}$ Deste modo, a apreensão do seu verdadeiro sen-

\footnotetext{
5 Idem, p. 94

${ }^{6}$ Idem, p. 44

${ }^{7}$ Idem, p. 199

${ }^{8}$ Idem, p. 199
} 
tido pró́be a separação de significante e significado. Significa isto que a arte, enquanto apresentação de signos sensíveis, não nos remete para um mundo de objectos naturais nem para um mundo de objectos ideais. A arte não tem uma significação natural, na medida em não procura representar o mundo dos objectos reais, nem uma significação ideal, pois não remete para um mundo aberto ao entendimento. O sentido que o objecto estético torna presente nunca se esclarece na percepção de um objecto real, ou na intelecção de objectos ideais; o que a obra diz está radicalmente entretecido no seu apresentar-se, de tal modo não pode ser compreendido de outro modo. A sua vocação não é a de evocar realidades que lhe são transcendentes e susceptíveis de serem visadas por outros modos de apreensão.

Esta especificidade do objecto estético está bem patente na dificuldade que todos nós experimentamos quando alguém nos solicita a descrição do sentido de uma experiência estética pessoal. Por mais eloquentes que sejamos, sentimos sempre a impotência da linguagem para tornar presente a "coisa mesma», pela razão de que o sentido da obra reclama, para a sua revelação, o ser vivida por uma consciência. Isto significa que a verdade do objecto estético é irredutível a significados conceptuais susceptíveis de uma transmissão verbal, e que apenas se oferece sob a forma de uma atmosfera afectiva imanente ao seu desdobramento sensível. Assim, o discurso sobre a obra nunca a torna presente, e tudo o que sobre ela dissermos constitui-se inevitavelmente como uma pálida imagem da sua verdade.

Para elucidarmos o modo de significação do objecto estético, comecemos por considerar o caso da pintura representativa. Recordemos, a esse propósito, a tese platónica, segundo a qual a arte é imitação do real. Nesse caso, a verdade da pintura consistiria na representação pictórica, tão fiel quanto possível, de objectos reais, de tal modo que, na presença de tais objectos, toda a arte se apresentaria como uma reprodução inútil. Ora esta tese, como bem observa Dufrenne, dificilmente se compatibiliza com o facto de que, em larga medida, não é o critério da semelhança que orienta o trabalho dos pintores. Assim sendo, somos levados a suspeitar que a representação não está ao serviço do mundo, e que portanto a significação do objecto estético «não implica a imitação, pelo objecto representado, de um objecto ou acontecimento do mundo»?

Decerto que um quadro também significa representando; assim, facilmente reconhecemos que o Quarto de Vicent em Arles, de Van Gogh, ${ }^{10}$ representa uma série de objectos reais, como uma cama ou uma cadeira. Todavia, o fundamental não está naquilo que representa, mas sim no modo como representa. Como compreender a sua dimensão estética caso se limitasse a

9 Idem, p. 166

10 Dado que Van Gogh elaborou três versões do mesmo quarto, importa especificar que nos referimos em particular à versão de Outubro de 1888 . 
uma reprodução banal de objectos quotidianos? Na verdade, o uso que Van Gogh faz da cor, dos empastamentos ou das linhas, na elaboração dos elementos representados, não serve de modo algum a produção de um efeito realista. As tonalidades quentes, as pinceladas vigorosas ou as linhas grossas que sublinham o contorno dos objectos combinam-se entre si como elementos expressivos, relegando para um plano secundário a exigências de uma fidelidade ao real. Desse modo, não só não podemos reduzir a significação de um quadro à sua dimensão representativa, enquanto cópia da realidade, como compreendemos que essa dimensão está ao serviço de uma significação superior, cuja natureza é a expressão. ${ }^{11}$

Vemos então que o objecto estético é significante essencialmente pela sua expressividade. Esta ideia sai especialmente reforçada quando nos debruçamos sobre uma arte não representativa como a música, em que o tratamento do sensível desenvolve uma plenitude de significação à revelia de quaisquer elementos representativos. A arte da música oferece-se assim como um caso paradigmático da autonomia do sensível no seu poder de significação. Existe sempre algo de misterioso nesse estado de suspensão em que nos quedamos, presos de uma trama de sons e silêncios que nos envolvem num mundo sem rostos nem nomes. Tudo o que se nos impõe é uma tonalidade afectiva, como o encantamento hipnótico das Gymnopédies de Satie, ou a melancolia romântica dos Nocturnos de Chopin.

A riqueza do sensível, diz-nos Dufrenne, traduz-se nessa qualidade afectiva que ele exprime, pelo que a sua magia consiste em comunicar um certo sentimento sem passar pelo conceito. ${ }^{12} \mathrm{E}$, de algum modo, a música dá um testemunho inequívoco de que assim é. Todavia, e como anteriormente observámos, o mesmo sucede na pintura representativa, desde que compreendamos que todos os elementos que a compõem colaboram na expressão de uma dimensão afectiva. Por esse motivo, ao contemplarmos a obra de Van Gogh a que anteriormente aludimos, sentimos que a simples percepção dos objectos representados se esbate pela emergência de um sentimento de angústia e crispação, de tal forma que o que acaba por predominar na nossa apreensão da obra é essa atmosfera afectiva, a despeito dos conteúdos representativos da obra.

Vemos pois que a pintura, independentemente da especificidade dos seus processos, tem, tal como a música, uma natureza expressiva. Dufrenne fala-nos assim deste parentesco: «o mundo de Cézanne, é a Provença, uma terra óssea e ardente, e de personagens que têm a opacidade imóvel dessa terra. Contudo, não podemos esquecer que é ainda outra coisa: que essas paisagens, naturais ou humanas, exprimem uma certa visão do mundo, compõem uma atmosfera à qual uma arte não representativa, como a música, nos 
faz aceder directamente». ${ }^{13}$ Se esta citação pretende, por um lado, ilustrar o que anteriormente foi dito, permite-nos também prosseguir na nossa reflexão ao introduzir a ideia de que a obra exprime o mundo do autor. A dimensão expressiva para que a obra nos desperta é aqui entendida como a apresentação de uma visão do mundo, como testemunho de um modo originário de relação com o mundo que se constitui sobretudo numa esfera afectiva. $\mathrm{Na}$ obra exprime-se a subjectividade do autor ao nível da sua relação mais originária com o mundo, e é a esse modo de ser que acedemos, por via do sentimento, quando deixamos que o objecto estético se nos revele na sua verdadeira significação.

\section{III - O mundo do objecto estético}

\section{A presença do autor na obra}

O mundo do objecto estético identifica-se pois com o mundo do seu autor; se ele é expressivo, é porque nele se exprime uma subjectividade. Todavia, é importante precisar qual a natureza da revelação em causa. Se a obra revela a verdade do autor, essa verdade «não é a verdade histórica do indivíduo real que é o objecto de uma biografia, é a verdade do homem presente à obra e que eu apenas conheço pela obra». ${ }^{14}$ Quando nos confrontamos com uma obra literária, são-nos por norma facultadas uma série de informações, nomeadamente vivências psicológicas do autor, as suas opiniões a propósito de acontecimentos históricos ou a sua perspectiva sobre o mundo social. De algum modo, podemos partir de todo este material para construir a identidade do autor da obra. Todavia, não é através deste tipo de exercício que acedemos àquilo que Dufrenne entende como a verdade do mundo do autor. Se assim fosse, como poderíamos falar de um mundo de Debussy, ou de um mundo de Mahler? Se é verdade que uma arte como a música nos pode levar à presença do autor, teremos que reconhecer que aquilo que na obra permite uma tal revelação excede sempre o dito ou o representado. Trata-se pois de algo mais subtil e fundamental, mas que se afirma inequivocamente como o traço marcante da obra; é neste ponto que Dufrenne introduz a noção de «estilo» como sendo «o lugar onde aparece o autor». ${ }^{15}$

Na música, como em todas a artes, existe todo um conjunto de processos técnicos associados à elaboração da obra. Todo o compositor parte de uma herança, herança essa que é constituída pelas técnicas de composição disponíveis no seu tempo. Do ponto de vista académico, a obra pode nascer como simples aplicação de um conjunto de princípios previamente dado. Todavia, é preciso algo mais para que a obra produzida não se resuma a uma

\footnotetext{
13 Idem, pp. 248-249

14 Idem, p. 159

15 Idem, p. 150
} 
realização meramente mecânica, e para que nela pressintamos a singularidade do seu autor. Não que isso implique uma ruptura com a tradição recebida, mas sem dúvida que requer uma apropriação pessoal que não a perpetue como repetição de fórmulas gastas, isto é, exige que a tradição e os meios técnicos que ela nos disponibiliza estejam «ao serviço de uma ideia ou visão singulares». ${ }^{16}$ A questão do estilo radica neste imperativo, pelo qual o aprendido tem que ser transformado à luz de uma subjectividade, de modo a que obra de arte seja testemunha de uma presença singular, e só na medida em que isto acontece é que podemos falar de uma obra como expressão de um mundo pessoal. O estilo compreende-se então como um modo próprio de tratar os materiais específicos a cada tipo arte, modo esse que radica e exprime um modo singular de ser no mundo. Penetrar no mundo da obra é assim aceder à presença do autor na verdade da sua relação viva com o mundo, verdade de carácter afectivo que apenas a arte pode exprimir.

\section{O objecto estético como mundo}

Importa agora compreender em que sentido podemos falar de um mundo do objecto estético. Vimos anteriormente que a sua significação tem a natureza da expressão, e que aquilo que é exprimido consiste essencialmente numa atmosfera afectiva. Finalmente, considerámos essa dimensão afectiva, comunicada ao espectador por via do sentimento, como a verdade de uma presença na qual o autor da obra se revela, não dum ponto de vista histórico ou psicológico, mas naquilo que traduz a singularidade do seu modo de ser no mundo. É isto que pretendemos significar quando dizemos que o objecto estético transporta consigo o mundo do autor. ${ }^{17}$ Todavia, para melhor compreendermos o sentido de tal afirmação, importa saber em que medida uma qualidade afectiva, elemento fundamental que apreendemos na experiência estética, pode estar na origem de uma visão do mundo. Neste ponto, Dufrenne assume explicitamente a sua dívida para com o pensamento de Heidegger, atribuindo ao objecto estético algo como a transcendência do Dasein. $^{18}$

A expressão «transcendência do Dasein» traduz o reconhecimento de que o ser do homem consiste em estar referido a possibilidades a partir das quais se projecta um mundo. Assim, o Dasein está sempre comprometido com uma determinada pré-compreensão, à luz da qual se lhe revelam os entes mundanos. Essa pré-compreensão consiste num mundo de relações e referências, intimamente associada à historicidade do Dasein, que funciona

\footnotetext{
16 Idem, p. 150

17 Idem, p. 258

18

Idem, p. 247
} 
como um horizonte que possibilita e configura o nosso modo originário de encontrarmos as coisas. Deste modo somos conduzidos a uma noção de mundo que, ao invés de designar a totalidade dos entes, se compreende como condição de possibilidade do seu aparecer; como observa Heidegger, «o ente não se poderia manifestar de modo algum se não pudesse entrar num mundo» ${ }^{19}$. Vemos assim que a estrutura da pré-compreensão funciona como um a priori a partir do qual os entes se nos dão, enquanto integrados num mundo de significações. Contudo, tão ou mais fundamental do que a estrutura da pré-compreensão, é a estrutura do encontrar-se afectado, isto é, a tonalidade afectiva em que o homem, enquanto ser no mundo, sempre se encontra. $^{20}$

Diz Heidegger que «a tonalidade afectiva abriu já sempre o Dasein ao mundo na sua totalidade, tornando assim possível um dirigir-se para» ${ }^{21}$, e ainda que «no plano ontológico fundamental, devemos confiar a descoberta originária do mundo à simples tonalidade afectiva» ${ }^{22}$. Assim sendo, além de se caracterizar por ter sempre uma certa compreensão de uma totalidade de significados, o Dasein, enquanto ser no mundo, tem sempre uma tonalidade afectiva, sendo que esta afectividade é ela mesma uma espécie de a priori ainda mais originário do que a compreensão. É este a priori afectivo que se constitui como a luz ou abertura fundamental a partir da qual é possível a revelação dos entes. De notar ainda que tanto o a priori da compreensão como o a priori afectivo não têm uma dimensão transcendental, mas sim existencial, o que implica reconhecer-lhes uma natureza essencialmente dinâmica. Assim, ao Dasein está sempre aberta a possibilidade de uma nova experiência de si e do mundo, consoante a luz a partir da qual o coisas se lhe iluminam.

Regressemos agora a Dufrenne, tentando compreender em que consiste o mundo do objecto estético. A experiência estética, como referimos, dá-nos essencialmente acesso a uma atmosfera afectiva, que podemos agora compreender como o a priori afectivo do seu autor. Ao exprimir esse a priori, o objecto estético traz-nos à presença a verdade de um mundo na sua dimensão mais originária, mas, e sublinhando um aspecto que é decisivo, devemos compreender que essa presença apenas se realiza na medida em que uma tal verdade se assume para o espectador como uma possibilidade própria. Pressentimos aqui em que consiste a radicalidade de uma tal experiência, dado que ela implica uma transformação da subjectividade ao nível dos a priori

19 Passagem oriunda de da obra de Heidegger $O$ que é a metafísica?, e que Dufrenne cita no seu próprio texto, na página 247.

20 Heidegger, El Ser y el Tiempo, trad. José Gaos, Madrid, Fondo de Cultura Económica, 1993, p. 151

21 Idem, p. 154

22 Idem, p. 155 
que, simultaneamente, traçam os contornos da sua experiência de si e do mundo. Só deste modo é que a obra de arte passa de exigência a realização, recebendo densidade existencial através da experiência vivida de uma consciência. Para que a obra seja em nós, ou, como prefere dizer Dufrenne, para que nós sejamos na obra, ${ }^{23}$ formulação que exprime melhor esse renascer da subjectividade à luz de um novo a priori afectivo, impõe-se pois como necessária a suspensão de todas as significações prévias que configuram o nosso actual modo de ser no mundo. Só a disponibilidade para uma tal experiência possibilita que a obra de arte nos surja como objecto estético, oferecendo-se-nos então como abertura a novos sentidos, como uma atmosfera ou promêssa de mundo, um mundo ainda não povoado de objectos, mas que os precede, que é como uma clareira onde eles se revelam. ${ }^{24}$

\section{Abstract}

With this article we intend to explore the concept of «esthetical object» proposed in Dufrenne`s text entitled La Phénoménologie de l'experience estéthique I.

The potentiality/activity binomial appears as the ground for Dufrenne`s definition of esthetical object as perceived work of art. According to this, the happening of any artwork truly finds its proper place in esthetical experience, which arises as the meeting point of art's expressive potentiality and the spectator's perception act. Establishing an accurate distinction between esthetical perception and other kinds of human perception, Dufrenne sees the former as the pure presence of the sensitive. Advocating the inseparability of significant and signification for the esthetical object, the author declares the meaning of esthetical experience as immanent to its own sensitive presentation.

Dufrenne presents authentic esthetical perception as something, which has the power to engage subjectivity in a radical experience. Under the light projected by the work of art, human beings are enabled to actualise other modes of being-in-the-world. With expression as its proper signifying mode, the esthetical object reveals itself as a world beginning, proposing an affective atmosphere, which opens the subject of esthetical experience to new existential possibilities.

\footnotetext{
23 Mikel Dufrenne, Op. cit, p. 97

24 Idem, p. 239
} 